\title{
The influence of physical state on shikimic acid ozonolysis: a case for in situ microspectroscopy
}

\author{
S. S. Steimer ${ }^{1,2}$, M. Lampimäki ${ }^{1, *}$, E. Coz ${ }^{3}$, G. Grzinic ${ }^{1,4}$, and M. Ammann ${ }^{1}$ \\ ${ }^{1}$ Paul Scherrer Institute, Laboratory of Radio- and Environmental Chemistry, 5232 Villigen PSI, Switzerland \\ ${ }^{2}$ Swiss Federal Institute of Technology Zurich, Institute for Atmospheric and Climate Science, \\ 8092 Zurich, Switzerland \\ ${ }^{3}$ Centro de Investigaciones Energéticas, Medioambientales y Tecnológicas, Department of the Environment, \\ 28040 Madrid, Spain \\ ${ }^{4}$ University of Bern, Department of Chemistry and Biochemistry, 3012 Bern, Switzerland \\ *now at: University of Helsinki, Viikki Teacher Training School, 00014 University of Helsinki, Finland
}

Correspondence to: S. S. Steimer (sarah.steimer@psi.ch)

Received: 25 February 2014 - Published in Atmos. Chem. Phys. Discuss.: 18 March 2014

Revised: 20 August 2014 - Accepted: 3 September 2014 - Published: 13 October 2014

\begin{abstract}
Atmospheric soluble organic aerosol material can become solid or semi-solid. Due to increasing viscosity and decreasing diffusivity, this can impact important processes such as gas uptake and reactivity within aerosols containing such substances. This work explores the dependence of shikimic acid ozonolysis on humidity and thereby viscosity. Shikimic acid, a proxy for oxygenated reactive organic material, reacts with $\mathrm{O}_{3}$ in a Criegee-type reaction. We used an environmental microreactor embedded in a scanning transmission X-ray microscope (STXM) to probe this oxidation process. This technique facilitates in situ measurements with single micron-sized particles and allows to obtain near-edge X-ray absorption fine structure (NEXAFS) spectra with high spatial resolution. Thus, the chemical evolution of the interior of the particles can be followed under reaction conditions. The experiments show that the overall degradation rate of shikimic acid is depending on the relative humidity in a way that is controlled by the decreasing diffusivity of ozone with decreasing humidity. This decreasing diffusivity is most likely linked to the increasing viscosity of the shikimic acidwater mixture. The degradation rate was also depending on particle size, most congruent with a reacto-diffusion limited kinetic case where the reaction progresses only in a shallow layer within the bulk. No gradient in the shikimic acid concentration was observed within the bulk material at any humidity indicating that the diffusivity of shikimic acid is still high enough to allow its equilibration throughout the parti-
\end{abstract}

cles on the timescale of hours at higher humidity and that the thickness of the oxidized layer under dry conditions, where the particles are solid, is beyond the resolution of STXM.

\section{Introduction}

Atmospheric aerosols are an important focus of environmental research due to their effect on atmosphere, climate and health (Pöschl, 2005). It has been shown that organic matter can account for a significant and sometimes major mass fraction of aerosols, depending on location (Kanakidou et al., 2005; Zhang et al., 2007). Around 20-70\% of organic particulate matter is comprised of water soluble organics, such as carboxylic acids, polyols, polyphenols, sugars and other highly functionalized compounds (Rogge et al., 1993; Saxena and Hildemann, 1996; Decesari et al., 2000). It was recently shown that aqueous solutions and solution droplets of such organics are likely to form glasses or highly viscous amorphous semi-solids such as rubbers, gels and ultraviscous liquids under atmospherically relevant conditions (Murray, 2008; Zobrist et al., 2008; Mikhailov et al., 2009). Additionally, recent experimental findings both from field and laboratory measurements suggest an amorphous solid state for organic aerosols (Virtanen et al., 2010; Saukko et al., 2012). Amorphous solids and semi-solids are highly viscous. Solid glasses have viscosities $\geq 10^{12} \mathrm{~Pa}$ s (Debenedetti and 
Stillinger, 2001), while the viscosity of semi-solids is lower ( $>10^{10}$ to $>10^{4} \mathrm{Pas}$ ) (Mikhailov et al., 2009) but still high compared to liquid water $\left(\sim 10^{-3} \mathrm{Pas}\right)$. At high viscosities, diffusion is significantly slower, which is likely to decrease the reaction rate, diminish water uptake, inhibit ice nucleation and influence the formation and growth of secondary organic aerosol (SOA) (Shiraiwa et al., 2011; Zobrist et al., 2011; Mikhailov et al., 2009; Murray, 2008; Perraud et al., 2012; Shiraiwa and Seinfeld, 2012). Reactions within the bulk of aerosol particles are dependent on diffusion of reactive molecules (oxidant gases) into the bulk. If viscosity is too high, diffusion could become the rate limiting process. This phenomenon is well known for crystalline solids, where reactivity is generally limited to the surface (Moise and Rudich, 2002; Renbaum and Smith, 2009). Therefore, formation of amorphous solids and semi-solids should severely slow down or even inhibit reactions. This change in reactivity has important implications for the lifetime of particles and their constituents and the particles' physical and chemical properties. It is therefore necessary to thoroughly investigate the existence and extent of the influence of the physical state on reactivity. First indications of such a link between physical state and reactivity were shown by Shiraiwa et al. (2011). In their study, the authors used a kinetic model (KM-SUB) (Shiraiwa et al., 2010) to evaluate experimental data from flow tube experiments of ozonolysis of thin protein films and obtain information on the kinetic regimes as a function of viscosity. The temporal behavior of the uptake coefficient was interpreted as driven by diffusion in the condensed phase. Since then, only two additional studies, both of them using aerosol flow tubes and mass spectrometric detection, have been conducted: a study by Kuwata and Martin (2012) proposing a connection between physical state and the formation rate of organonitrates in $\alpha$-pinene SOA and one by Zhou et al. (2013), showing that the extent of the reaction of benzo[a]pyrene with ozone $\left(\mathrm{O}_{3}\right)$ is limited by diffusion through SOA coatings at humidities of $50 \%$ and lower.

When studying the effects of physical state on the reactivity of aerosol particles, direct observation of the bulk reaction would be of an advantage. In near-edge X-ray absorption fine structure (NEXAFS) spectroscopy, core electrons are excited into unoccupied orbitals, resulting in resonant absorption peaks around the element specific ionization threshold (absorption edge). This resulting fine structure can be used to distinguish different functional groups (Hopkins et al., 2007; Takahama et al., 2007; Pöhlker et al., 2012). Scanning transmission X-ray microscopy (STXM) is a microscopy technique which offers a high spatial resolution of down to less than $20 \mathrm{~nm}$ (Raabe et al. 2008) though it is usually more around $30 \mathrm{~nm}$ for environmental applications (Bluhm et al. 2006). Combining the spectroscopic technique with microscopy therefore offers the possibility to measure chemical maps at this high spatial resolution (Russell et al., 2002; Maria et al., 2004; Moffet et al., 2010, 2013) that cannot be achieved by optical methods such as Raman mi-

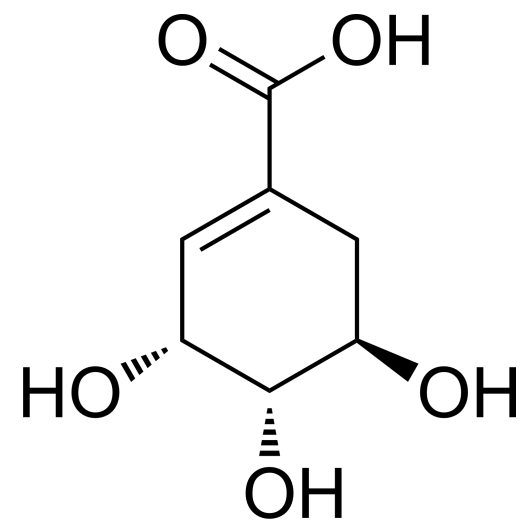

Figure 1. Structure of shikimic acid.

croscopy (Ivleva et al., 2007; Yeung et al., 2009). Since the ionization edge of carbon lies in the soft X-ray regime, carbon NEXAFS measurements are usually performed in vacuum to avoid absorption of the incident beam by air. To facilitate STXM/NEXAFS measurements of single particles under in situ exposure to various gases, we have developed an environmental microreactor (Huthwelker et al., 2010) based on a design by Drake et al. (2004). Our reactor has so far been used to observe water uptake on ammonium sulfate and mixed ammonium sulfate/adipic acid (Zelenay et al., 2011a) and soot particles (Zelenay et al., 2011c), as well as humidity driven chemical separation of complex organic matter such as fulvic and tannic acid (Zelenay et al., 2011b). A reactor of similar design with an in cell humidity probe was recently developed and characterized by Kelly et al. (2013). We have now utilized our microreactor to observe the ozonolysis of single shikimic acid particles in situ and under different relative humidities, to provide new insights into the dependence of reactivity on physical state. While Drake et al. (2004) have already used their cell to monitor oxidation state changes in a silica-supported copper catalyst, this is to our best knowledge the first successful application of STXM/NEXAFS to observe a chemical reaction of an environmentally relevant organic material in situ. The organic compound in question, shikimic acid $((3 R, 4 S, 5 R)-3,4,5$-trihydroxycyclohex-1-ene1-carboxylic acid, Fig. 1), was chosen as a proxy for oxygenated organic material and has been shown to be present in biomass burning aerosol (Medeiros and Simoneit, 2008). Shikimic acid undergoes humidity dependent changes in physical state (Steimer et al., 2014) and both shikimic acid as well as its first generation ozonolysis products are unlikely to be volatile, making it a suitable compound for a STXM investigation of the influence of physical state on reactivity. 


\section{Experimental section}

\subsection{Sample preparation}

Shikimic acid ( $\geq 99 \%)$ was purchased from Sigma-Aldrich and used without further purification. Aerosol particles were generated by nebulizing a solution containing a few grams per liter of shikimic acid in ultrapure water $(18 \mathrm{M} \Omega \mathrm{cm}$, MilliQ) with a custom-built ultrasonic particle generator. The particles were then dried with a Nafion membrane diffusion drier, charge equilibrated by passing them through a $\mathrm{Kr}-85$ source and size-selected using a differential mobility analyzer (DMA) at a voltage of $1.9 \mathrm{kV}$. The selected particles were counted with a condensation particle counter (CPC) and deposited via impaction on a silicon nitride $\left(\mathrm{Si}_{3} \mathrm{~N}_{4}\right)$ membrane supported by a Si window frame, which is attached to the removable front piece of the environmental microreactor.

\subsection{Environmental microreactor}

Usage of an environmental microreactor made it possible to expose the particles to various gases within a temperature and humidity controlled environment during microspectroscopy measurements. A detailed description of the reactor can be found elsewhere (Huthwelker et al., 2010). Briefly, the microreactor consists of two main parts: a removable front piece, holding the window on which the sample is deposited, and the body. The latter includes a gas inlet and outlet and is capped with another window. These windows consist of $5 \mathrm{~mm} \times 5 \mathrm{~mm}$ silicon frames with small openings in the center $(0.5 \mathrm{~mm} \times 0.5 \mathrm{~mm}$ front window, $1 \mathrm{~mm} \times 1 \mathrm{~mm}$ back window) supporting $50 \mathrm{~nm}$ thick $\mathrm{Si}_{3} \mathrm{~N}_{4}$ membranes. They are attached to the cell with wax (crystal bond 509, SPI suppliers). The front piece is mounted onto the main body with screws, resulting in a leak tight chamber of about $300 \mu \mathrm{m} \times 5 \mathrm{~mm} \times 5 \mathrm{~mm}$ inner dimensions which is permeable to $\mathrm{X}$-rays through the windows aligned along the beam axis. The cell was left at room temperature during the present measurements. Temperature was constantly monitored with a thermocouple attached to the reactor body. The atmosphere within the reactor was adjusted by varying the flow of the different gases used in this study. The two main gases were helium $(\mathrm{He})$ and oxygen $\left(\mathrm{O}_{2}\right)$ used at ratios from $4: 1$ to $7: 1$. Part of the oxygen was converted to ozone $\left(\mathrm{O}_{3}\right)$ using an adjustable $\mathrm{O}_{3}$ generator based on a mercury UV lamp resulting in ozone partial pressures of $2.5 \times 10^{-6}$ to $6.5 \times 10^{-6} \mathrm{~atm}$. The $\mathrm{O}_{3}$ concentration was measured at the exhaust of the reactor with a home-built UV absorption setup, which was calibrated with a commercial ozone analyzer (Model 400E UV Absorption $\mathrm{O}_{3}$ Analyzer, Teledyne-API). We neglect loss of $\mathrm{O}_{3}$ to tubing and the microreactor as we assume passivation to be fast at these high concentrations. Humidity was adjusted by passing a variable fraction of the He flow through a humidifier. Experiments were conducted at four different relative humidities (RH): $12 \%, 52 \%, 71 \%$ and $82 \%$. RH was measured using capacitance sensors at the entrance and exit of the microscope chamber. The sensors were operated at room temperature and regularly compared to a dewpoint sensor (DewMaster, EdgeTech). The relative humidity in the microreactor was calculated from the capacitance sensor output by taking into account the microreactor temperature measured by the thermocouple and the small but measurable pressure drop between inlet and outlet. The pressure within the reactor was set to 150 mbar throughout all experiments.

\subsection{STXM-NEXAFS}

All measurements were performed at the PolLux beam line (X07DA) of the Swiss Light Source (SLS) at Paul Scherrer Institute, Switzerland. This beam line provides photons with an energy range of 200-1400 eV at an energy resolution $(E / \Delta E)$ of about 3000 . The end station is a STXM (Raabe et al., 2008) with a spatial resolution of about $40 \mathrm{~nm}$ under the conditions of the present experiments. Additional energy calibration of spectra beyond the routine calibration of the beam line was done by comparing the measured lowest energy peak of polystyrene with its literature value $(285.18 \mathrm{eV})$ (Dhez et al., 2003). To convert from transmission to absorption and normalize spectra and images to the incident light intensity, the Lambert-Beer law (OD $\left.=-\ln \left(I / I_{0}\right)=d \mu\right)$ was used. Here OD is the optical density, $\mu$ the linear absorption coefficient, $d$ the thickness of the sample, $I$ the transmitted light intensity through the particle and $I_{0}$ the incident light intensity. Two different modes of measurement were employed during the experiments. Carbon spectra were measured in image stack mode, in which a series of images is taken at closely spaced energy steps, yielding spatially resolved spectra (Jacobsen et al., 2000). The step sizes for the present experiments were $1 \mathrm{eV}$ in the range of $280-284 \mathrm{eV}$, $0.2 \mathrm{eV}$ in the range of $284.1-290 \mathrm{eV}$ and $1.9 \mathrm{eV}$ in the range of $291-320 \mathrm{eV}$, with a dwell time of $1 \mathrm{~ms}$ for each energy. The spatial resolution was either $30 \times 30$ or $40 \times 40$ pixels over a rectangular area typically 3 to $5 \mu \mathrm{m}$. Spatial as well as energy resolution were kept relatively low to increase time resolution and, in addition with the low dwell time, avoid beam damage. For a less noisy, well-resolved line spectrum of shikimic acid, see Supplement Fig S2. To obtain chemical maps, stacks of transmission images with higher spatial resolution $(65 \times 65$ or $70 \times 70$ pixels $)$ were measured at only few selected energies: $279.5 \mathrm{eV}, 281.5 \mathrm{eV}$ (pre edge), $284.1 \mathrm{eV}$, $284.2 \mathrm{eV}, 284.3 \mathrm{eV}, 284.4 \mathrm{eV}\left(1 \mathrm{~s}-\pi^{*}\right.$ transition peak) and $311.0 \mathrm{eV}, 319.5 \mathrm{eV}$ (post edge), all with a dwell time of $3 \mathrm{~ms}$. These images were then converted to OD images. The spatial distribution of the double bond of shikimic acid within a particle was assessed by calculating the ratio of the preedge subtracted image at peak maximum of the $1 \mathrm{~s}-\pi^{*}$ transition peak to that of the pre-edge subtracted total carbon yield images. Since dividing the small values of the backgrounds of the OD images leads to large noise in the chemical maps, the background was masked to enhance visibility 


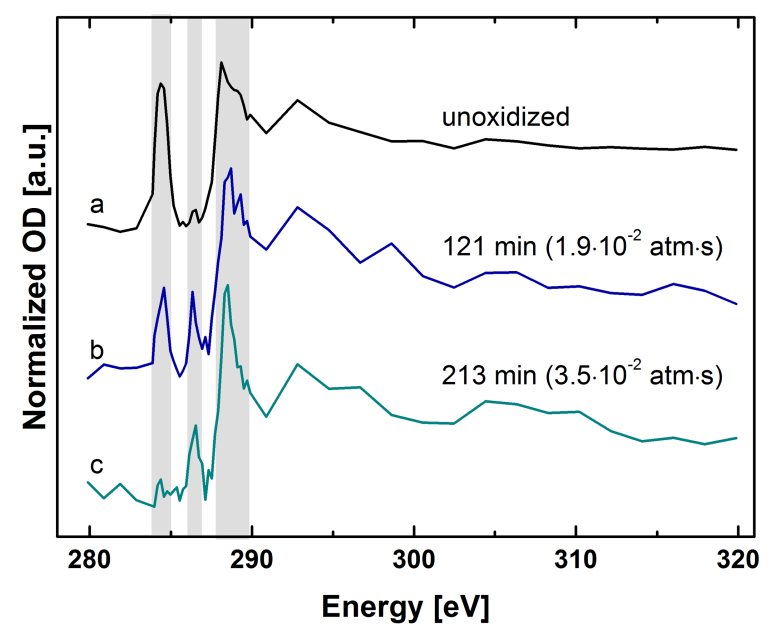

Figure 2. Averaged spectra of single particles before and after oxidation at a relative humidity of $82 \%$. The grey areas denote regions in which spectral changes can be observed. The main feature of the oxidation is the decrease of the $1 \mathrm{~s}-\pi^{*}$ peak at $284.4 \mathrm{eV}$.

of the particles. The border between background and particle was drawn manually, judging by eye where the region of neighboring extreme values begins. Integration of these images yields radial profiles, which provide information about the radial distribution of the double bond at a higher signalto-noise ratio. Additionally, low resolution spectra were extracted from these image series to provide additional data for the analysis of the humidity and size dependence of the shikimic acid degradation. All spectra were normalized by the averaged post-edge absorption at $310-320 \mathrm{eV}$. Particles were always only measured once to avoid any effect of beam damage on the retrieval of degradation rates. Due to carbon contamination along the beam line, optical elements and windows, and the influence of small amounts of higherorder light, all measured spectra shown are slightly distorted around the carbon K-edge (near $290 \mathrm{eV}$ ), where only little light reaches the sample and greater relative proportion of higher-order light leads to an apparently lower absorption. This should, however, not affect the regions of the spectra used for data analysis (see Supplement). All data analysis was done using aXis2000 (Hitchcock, 1998).

\section{Results and discussion}

\subsection{Evolution of carbon NEXAFS spectra during ozonolysis}

Shikimic acid is oxidized upon exposure to $\mathrm{O}_{3}$ (Fig. 2). Spectrum (a) shows the averaged NEXAFS carbon K-edge spectrum of dry, fresh shikimic acid particles. The main identifiable feature is the $1 \mathrm{~s}-\pi^{*}$ transition at $284.4 \mathrm{eV}$. Upon oxidation at $82 \% \mathrm{RH}$ (spectrum $\mathrm{b}$ and c), this peak decreases since the shikimic acid double bond is broken in a Criegee reaction
(Criegee, 1975). This demonstrates our ability to monitor the degradation by STXM/NEXAFS in situ. Apart from the decrease at $284.4 \mathrm{eV}$, two additional changing features can be observed: the appearance of a small peak at $286.4 \mathrm{eV}$ and an increase as well as a small shift of the carboxyl peak at $288.2 \mathrm{eV}$. The appearance or increase of these two peaks is indicative of an increase in oxidized bonds. Additional oxygen functionality is consistent with secondary chemistry during condensed phase ozonolysis of alkenes (Zahardis and Petrucci, 2007). We refrain from further interpreting these peaks in terms of different conceivable products. Since it is easiest to identify and least likely to be affected by beam line contamination (see Supplement for discussion and an example of a less affected spectrum - Supplement Fig. S2), the decrease of the $1 \mathrm{~s}-\pi^{*}$ transition peak was chosen to quantitatively follow the progression of the reaction. Note that the spectra are normalized to the averaged absorption between 310 and $320 \mathrm{eV}$, i.e., total carbon, so that the peak height of the $1 \mathrm{~s}-\pi^{*}$ transition is proportional to the shikimic acid concentration in an individual particle and differences in particle size are accounted for.

\subsection{Humidity dependence}

The evolution of the $1 \mathrm{~s}-\pi^{*}$ transition peak with exposure to $\mathrm{O}_{3}$ was monitored at four different relative humidities: $12 \%$, $52 \%, 71 \%$ and $82 \%$. This was done by normalizing the peak height per particle after a certain time of oxidation to the average initial height measured in particles prior to oxidation at this humidity (Fig. 3a). Peak height per particle was calculated as an average over the projected particle area. The ratio of the two peak heights before and after oxidation equals the relative loss of shikimic acid $[\mathrm{Y}]_{\mathrm{b}} /[\mathrm{Y}]_{\mathrm{b}, 0}$, where $[\mathrm{Y}]_{\mathrm{b}}$ is the current bulk concentration of shikimic acid of the measured particle and $[\mathrm{Y}]_{\mathrm{b}, 0}$ the associated average initial bulk concentration. In other words, for one sample, after taking spectra on a number of particles (2-9) to determine the average signal proportional to the initial concentration $[\mathrm{Y}]_{\mathrm{b}, 0}$, exposure starts at the same time for all particles, but the signal proportional to $[\mathrm{Y}]_{\mathrm{b}}$ is quantified for different other individual particles at different times, i.e., [Y $]_{b}$ is only measured once for each individual particle. Therefore, each data point in Fig. 3 represents the ratio $[\mathrm{Y}]_{\mathrm{b}} /[\mathrm{Y}]_{\mathrm{b}, 0}$ for a different particle. Beam damage prevents observing the degradation for the same particle over longer times.

Figure 3 clearly demonstrates that the degradation rate of shikimic acid is depending on humidity. In the following, the degradation rate laws are discussed for different conceivable kinetic regimes. Assuming a pseudo-first-order reaction, the depletion rate is linearly dependent on $[\mathrm{Y}]_{\mathrm{b}}$ (Eq. 1)

$$
\begin{aligned}
\frac{\mathrm{d}[\mathrm{Y}]_{\mathrm{b}}}{\mathrm{d} t} & =-k^{\mathrm{II}}\left[\mathrm{O}_{3}\right]_{\mathrm{b}}[\mathrm{Y}]_{\mathrm{b}}=-k^{\mathrm{II}} H_{\mathrm{O}_{3}} p_{\mathrm{O}_{3}}[\mathrm{Y}]_{\mathrm{b}} \\
& =-k_{\mathrm{Y}}^{\mathrm{I}}[\mathrm{Y}]_{\mathrm{b}},
\end{aligned}
$$




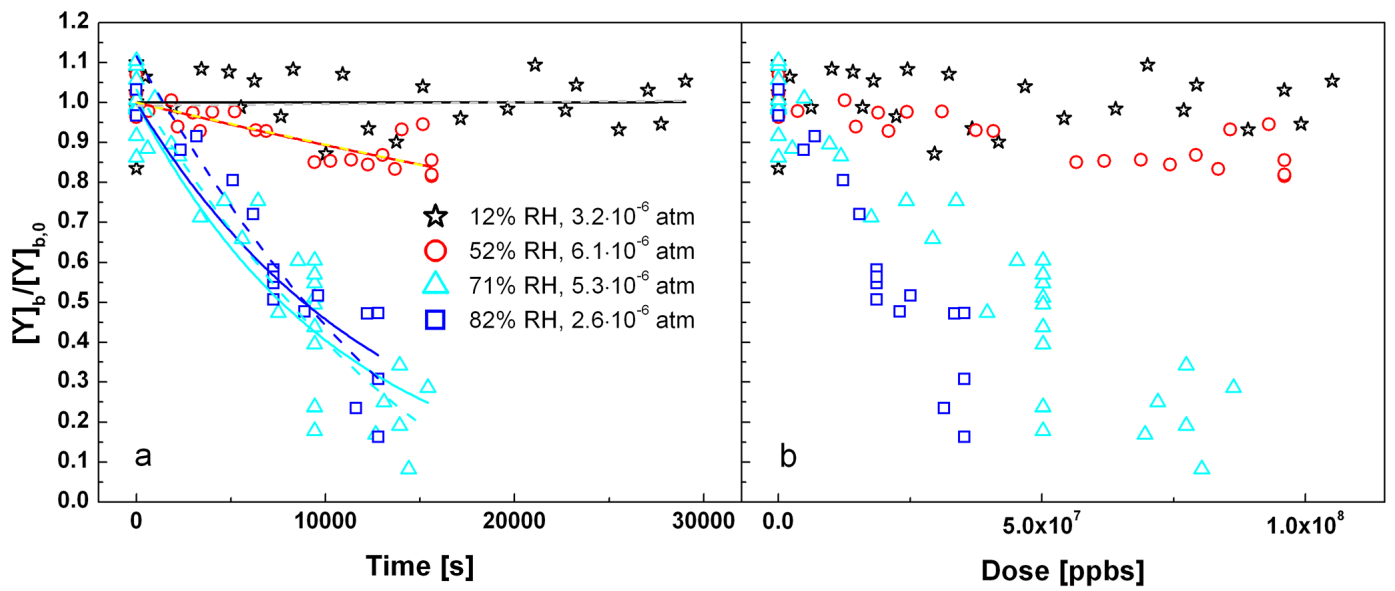

Figure 3. (a) Depletion of shikimic acid as a function of exposure time via the decrease in the normalized OD at $284.4 \mathrm{eV}$ (relative loss). The depletion was measured at four different relative humidities. The lines show the respective fits for that humidity assuming pseudo-firstorder decay (black, red, blue and cyan, solid line) and reacto-diffusive limitation (grey, yellow, blue and cyan, dashed line). (b) Depletion of shikimic acid as a function of $\mathrm{O}_{3}$ dose via the decrease in the normalized $\mathrm{OD}$ at $284.4 \mathrm{eV}$ at four different relative humidities.

where $\left[\mathrm{O}_{3}\right]_{\text {b }}$ equals the $\mathrm{O}_{3}$ concentration in the aerosol bulk in $\mathrm{mol} \mathrm{L}^{-1}, k^{\mathrm{II}}$ the second order rate constant in $\mathrm{M}^{-1} \mathrm{~s}^{-1}$, $H_{\mathrm{O}_{3}}$ the Henry constant in $\mathrm{mol} \mathrm{L}^{-1} \mathrm{~atm}^{-1}, p_{\mathrm{O}_{3}}$ the absolute pressure of $\mathrm{O}_{3}$ in the system in atm and $k_{\mathrm{Y}}^{\mathrm{I}}$ the pseudo-firstorder rate constant with respect to shikimic acid depletion in $\mathrm{s}^{-1}$. Solving the differential equation shows that the relative loss as a function of time can be fitted with an exponential decay (Eq. 2).

$$
\frac{[\mathrm{Y}]_{\mathrm{b}}}{[\mathrm{Y}]_{\mathrm{b}, 0}}=e^{-k_{\mathrm{Y}}^{\mathrm{I}} t}
$$

Equation (1) is valid, if the reactants $\left(\mathrm{O}_{3}\right.$ and $\left.\mathrm{Y}\right)$ remain well mixed throughout the particle volume and depletion is only limited by the rate of the reaction. This is referred to as the bulk reaction limited case (Berkemeier et al., 2013) or often also referred to as volume limited uptake. In contrast to that, if the reaction is fast compared to diffusion so that $\mathrm{O}_{3}$ does not reach far into the interior of the particle, the loss rate of $[\mathrm{Y}]_{\mathrm{b}}$ exhibits a square root dependence of $[\mathrm{Y}]_{\mathrm{b}}$ which is traditionally referred to as reacto-diffusive limitation (Eq. 3),

$$
\begin{aligned}
& \frac{\mathrm{d}[\mathrm{Y}]_{\mathrm{b}}}{\mathrm{d} t}=-H_{\mathrm{O}_{3}} \mathrm{RT} \sqrt{D_{\mathrm{O}_{3}} k_{\mathrm{b}}^{\mathrm{II}}} \frac{S_{\mathrm{p}}}{V_{\mathrm{p}}}\left[\mathrm{O}_{3}\right]_{\mathrm{g}} \sqrt{[\mathrm{Y}]_{\mathrm{b}}} \\
& =-k^{D} \sqrt{[\mathrm{Y}]_{\mathrm{b}}},
\end{aligned}
$$

where $R$ is the gas constant in $\mathrm{L}_{\text {atm K}}-1 \mathrm{~mol}^{-1}, D_{\mathrm{O}_{3}}$ the diffusion coefficient of $\mathrm{O}_{3}$ in the bulk in $\mathrm{cm}^{2} \mathrm{~s}^{-1},\left[\mathrm{O}_{3}\right]_{\mathrm{g}}$ the gas phase ozone concentration in $\mathrm{molL}^{-1}, S_{\mathrm{p}}$ the particle surface in $\mathrm{cm}^{2}$ and $V_{\mathrm{p}}$ the particle volume in $\mathrm{cm}^{3}$. The relative loss can then be described by a second order polynomial as a function of time (Eq. 4):

$$
\frac{[\mathrm{Y}]_{\mathrm{b}}}{[\mathrm{Y}]_{\mathrm{b}, 0}}=\left(\frac{-k^{D} t+2 \sqrt{[\mathrm{Y}]_{\mathrm{b}, 0}}}{2 \sqrt{[\mathrm{Y}]_{\mathrm{b}, 0}}}\right)^{2},
$$

which is a more general form of the equation described by Worsnop et al. for reacto-diffusive limitation in spherical particles (Worsnop et al., 2002). In this case $[\mathrm{Y}]_{\mathrm{b}, 0}$ is needed to fit the data; these concentrations at different humidities were derived from measurements of the growth of dry shikimic acid particles as a function of humidity in an electrodynamic balance (EDB) (Steimer et al., 2014). As one can see from comparison of the fits for the different kinetic regimes in Fig. 3a, the two regimes can not be distinguished with the available data. By fitting a linearized version of the respective integrated rate law to the measured data (Fig. 4), one can determine $k_{\mathrm{Y}}^{\mathrm{I}}\left[\mathrm{s}^{-1}\right]$ (Eq. 5)

$\ln \left(\frac{[\mathrm{Y}]_{\mathrm{b}}}{[\mathrm{Y}]_{\mathrm{b}, 0}}\right)=-k_{\mathrm{Y}}^{1} t$

and $k^{D}\left[\mathrm{~mol}^{0.5} \mathrm{~L}^{-0.5} \mathrm{~s}^{-1}\right.$ ] (Eq. 6)

$2 \sqrt{[\mathrm{Y}]_{\mathrm{b}}}-2 \sqrt{[\mathrm{Y}]_{\mathrm{b}, 0}}=-k^{D} t$

from the slope of the fits. The resulting rate constants are listed in Table 1. Using the relation of pseudo-first-order and second-order rate constant (Eq. 1) and the description of the uptake coefficient $\gamma$ for a bulk reaction limited system (Eq. 7):

$\gamma_{\mathrm{O}_{3}}=\frac{4 k^{\mathrm{II}} H_{\mathrm{O}_{3}} \mathrm{RT}[\mathrm{Y}]_{\mathrm{b}}}{\bar{c}} \frac{V_{\mathrm{p}}}{S_{\mathrm{p}}}$,

one can use the obtained data to calculate the uptake coefficient $\gamma$ (Eq. 8), which describes the net uptake to the particle normalized by the collision rate.

$\gamma_{\mathrm{O}_{3}}=\frac{4 k_{\mathrm{Y}}^{\mathrm{I}} \mathrm{RT}[\mathrm{Y}]_{\mathrm{b}}}{\bar{c} p_{\mathrm{O}_{3}}} \frac{V_{\mathrm{p}}}{S_{\mathrm{p}}}$ 

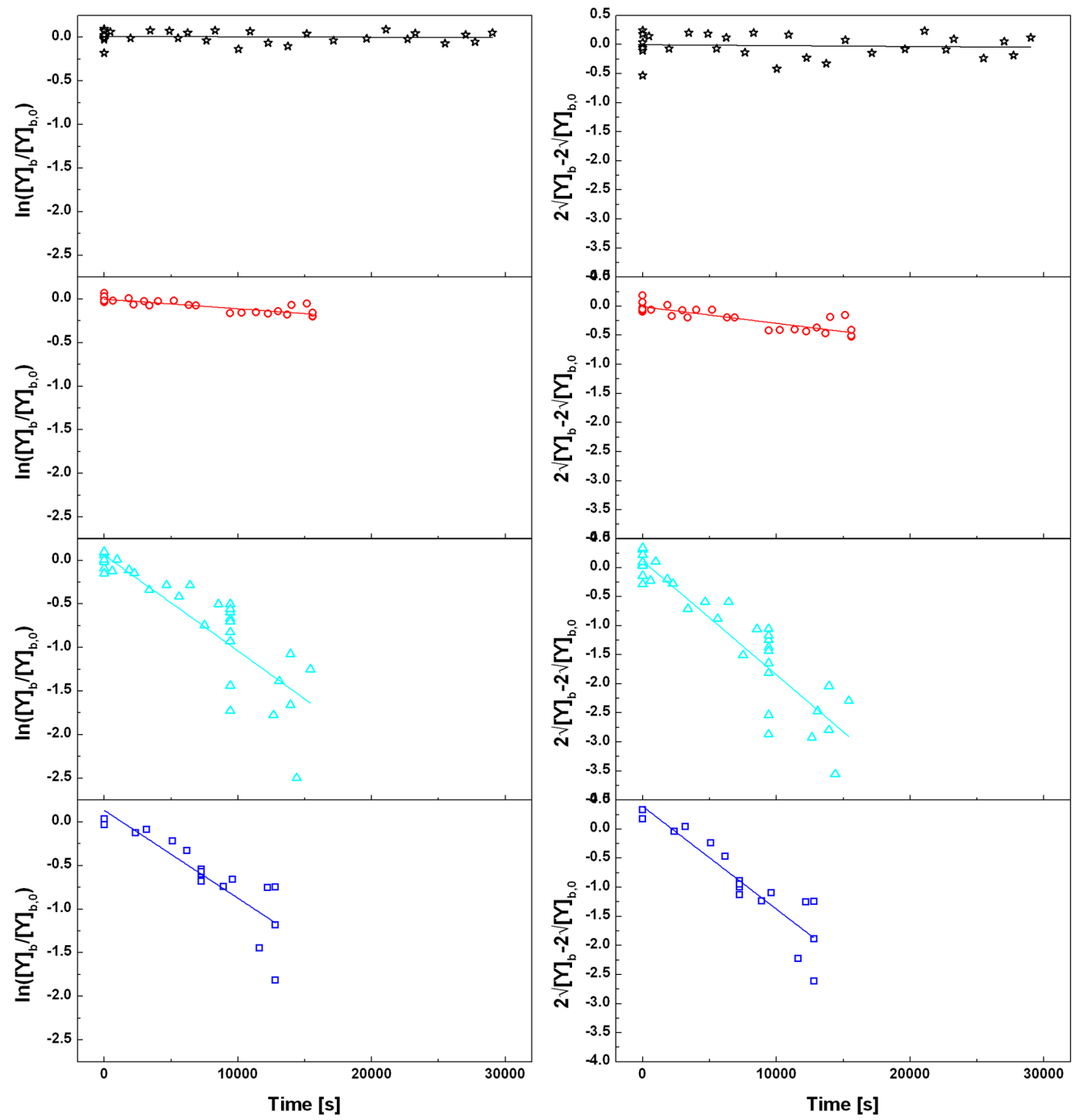

Figure 4. Linearized plots for pseudo-first-order volume limited (left) and reacto-diffusion limited reaction (right); linearized plots for the reacto-diffusive case: $12 \% \mathrm{RH}$ (black stars, $3.2 \times 10^{-6} \mathrm{~atm}$ ), $52 \% \mathrm{RH}$ (red circles, $6.1 \times 10^{-6}$ atm), $71 \% \mathrm{RH}$ (light blue triangles, $5.3 \times 10^{-6} \mathrm{~atm}$ ) and $82 \% \mathrm{RH}$ (blue squares, $2.6 \times 10^{-6} \mathrm{~atm}$ ). The slope of the linear fit equals the corresponding rate constant.

We thereby assume that the rate of disappearance of the double bond is equal to the rate of ozone uptake, i.e., no additional ozone loss occurs. The values obtained are also inherently linked to the assumption of the bulk reaction limited regime. The resulting values for $\gamma$ assuming a $1 \mu \mathrm{m}$ hemispherical particle can be found in Table 1 . The uptake varies by more than two orders of magnitude, from $5.8 \times 10^{-8}$ at $12 \% \mathrm{RH}$ to $9.0 \times 10^{-6}$ at $82 \% \mathrm{RH}$. Using the pseudo-firstorder rate constant determined at $82 \% \mathrm{RH}$ for the bulk reaction limited case and the Henry's law constant for $\mathrm{O}_{3}$ solubility in water at $298 \mathrm{~K}, 1.3 \times 10^{-2} \mathrm{M} \mathrm{atm}^{-1}$ (Utter et al., 1992), the second order rate constant of the reaction was calculated. With $k^{\mathrm{II}}=3 \times 10^{3} \mathrm{M}^{-1} \mathrm{~s}^{-1}$, the reactivity of shikimic acid with $\mathrm{O}_{3}$ is comparable to similarly functionalized compounds in aqueous solution, such as fumaric acid, where the reaction is about a factor of two faster $\left(6 \times 10^{3} \mathrm{M}^{-1} \mathrm{~s}^{-1}\right)$
(Hoigné and Bader, 1983). The rate constant for shikimic acid is about three orders of magnitude lower than that for oleic acid $\left(1 \times 10^{6} \mathrm{M}^{-1} \mathrm{~s}^{-1}\right.$; Razumovskii and Zaikov, 1980), a compound frequently used in aerosol chemistry to address condensed phase kinetics (Zahardis and Petrucci, 2007).

While a similar calculation could, in principle, also be done to extract $k^{\mathrm{II}}$ from $k^{D}$, the lack of data on the humidity dependent diffusion coefficient of $\mathrm{O}_{3}, D_{\mathrm{O}_{3}}$, prevents quantitative evaluation. When plotting against the total $\mathrm{O}_{3}$ dose instead of time to account for differences in $\mathrm{O}_{3}$ gas phase concentration, it can be clearly observed that the depletion rate increases with increasing humidity (Fig. 3b). For both bulk reaction limited and reacto-diffusion limited reaction (Eqs. 1 and 3), one would usually expect a decrease in reactivity with increasing humidity since the bulk concentration of shikimic acid decreases with increasing water 
Table 1. First order rate constants for the reaction limited case $\left(k^{\mathrm{I}}\right)$ and rate constants under reacto-diffusive limitation $\left(k^{D}\right)$ with standard error, determined from the linear fits and uptake coefficient for $\mathrm{O}_{3}$ on shikimic acid calculated assuming reaction limitation.

\begin{tabular}{cccccc}
\hline $\mathrm{RH}[\%]$ & $p_{\mathrm{O}_{3}}[\mathrm{~atm}]$ & {$[\mathrm{Y}]_{\mathrm{b}, 0}\left[\mathrm{~mol} \mathrm{~L}^{-1}\right]$} & $k^{\mathrm{I}}\left[\mathrm{s}^{-1}\right]$ & $k^{D}\left[\mathrm{~mol}^{0.5} \mathrm{~L}^{-0.5} \mathrm{~s}^{-1}\right]$ & $\gamma_{\mathrm{O}_{3}}$ \\
\hline 12 & $3.2 \times 10^{-6}$ & 8.4 & $4.9 \times 10^{-7}\left( \pm 1.3 \times 10^{-6}\right)$ & $1.5 \times 10^{-6}\left( \pm 3.8 \times 10^{-6}\right)$ & $5.8 \times 10^{-8}\left( \pm 1.6 \times 10^{-7}\right)$ \\
52 & $6.1 \times 10^{-6}$ & 7.3 & $1.1 \times 10^{-5}\left( \pm 1.2 \times 10^{-6}\right)$ & $2.8 \times 10^{-5}\left( \pm 3.1 \times 10^{-6}\right)$ & $5.9 \times 10^{-7}\left( \pm 1.1 \times 10^{-7}\right)$ \\
71 & $5.3 \times 10^{-6}$ & 6.3 & $1.1 \times 10^{-4}\left( \pm 1.1 \times 10^{-5}\right)$ & $2.0 \times 10^{-4}\left( \pm 1.5 \times 10^{-5}\right)$ & $5.9 \times 10^{-6}\left( \pm 1.1 \times 10^{-6}\right)$ \\
82 & $2.6 \times 10^{-6}$ & 5.2 & $1.0 \times 10^{-4}\left( \pm 1.5 \times 10^{-5}\right)$ & $1.8 \times 10^{-4}\left( \pm 2.1 \times 10^{-5}\right)$ & $9.0 \times 10^{-6}\left( \pm 2.2 \times 10^{-6}\right)$ \\
\hline
\end{tabular}

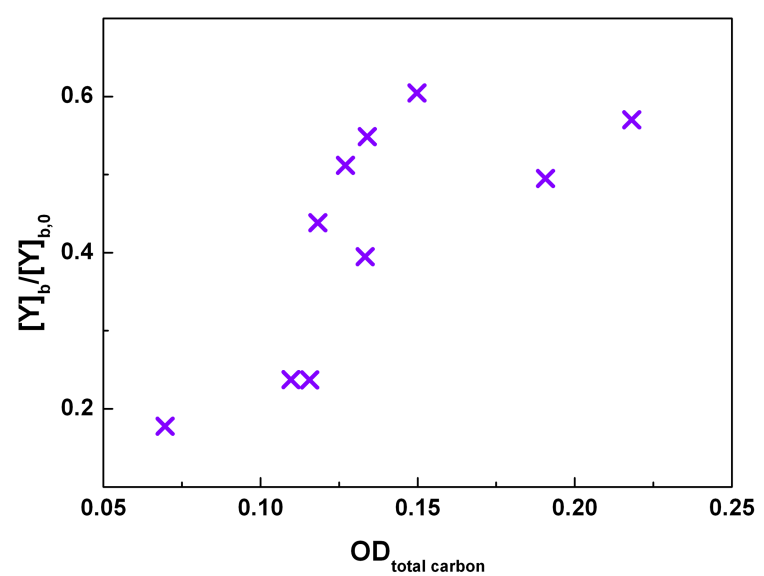

Figure 5. Size dependence of the oxidation rate: the amount of material already oxidized differs for particles of different thickness, all oxidized at $71 \% \mathrm{RH}$ with an ozone dose of $5.0 \times 10^{-2} \mathrm{~atm}$ s.

activity. One other parameter influencing the ozone uptake in both cases is the Henry constant. However, ozone solubility tends to be higher for liquid organics compared to water (Biń, 2006), so that one would generally expect a reactivity decrease with increasing humidity due to solubility decreasing towards that of pure water. As amorphous solids have only a small difference in free energy compared to the liquid, thermodynamic properties such as solubility should not be strongly affected and we expect the same trend for solubility of $\mathrm{O}_{3}$ in shikimic acid. Therefore, the trend of decreasing degradation rate with decreasing humidity goes in the opposite direction to that expected based on shikimic acid concentration and solubility for either of the kinetic regimes. However, the reacto-diffusive uptake (Eq. 3) is also influenced by the diffusion coefficient, $D_{\mathrm{O}_{3}}$. The degradation rate may become increasingly limited by diffusion towards lower humidity, because of the low diffusivity expected for the semi-solid and solid physical states that shikimic acid is likely to attain. If water acts as a plasticizer, the increasing humidity would lead to an increase in diffusivity, enabling a faster degradation rate. The fact that the reactivity increases with increasing water content in this experiment can therefore be seen as an indication for a reacto-diffusion limited regime showing a connection between physical state and reactivity. For simplicity, we assume that $H_{\mathrm{O}_{3}}$ remains the same for all humidi- ties and corresponds to the $\mathrm{O}_{3}$ solubility in water and that $k^{\mathrm{II}}$ derived for the volume limited case at $82 \%$ RH remains also the same for all conditions. If we thus assume that the reactivity change with humidity is solely due to changing diffusivity and shikimic acid concentration, we can estimate the range over which the diffusivity of ozone would need to change from humid to dry conditions from the values obtained for $k^{D} . D_{\mathrm{O}_{3}}$ would have to decrease from $7.6 \times 10^{-7}\left[\mathrm{~cm}^{2} \mathrm{~s}^{-1}\right]$ at $71 \% \mathrm{RH}$ to $1.2 \times 10^{-10}\left[\mathrm{~cm}^{2} \mathrm{~s}^{-1}\right]$ at $12 \% \mathrm{RH}$. The latter value is typical for small guest molecules in a glassy matrix (Koop et al., 2011). These estimates thus indicate that the changing degradation rate with humidity can be consistently interpreted in terms of the changing diffusivity likely caused by corresponding changes in viscosity.

\subsection{Size dependence}

By plotting the ratio of normalized $\mathrm{OD}$ at $284.4 \mathrm{eV}$ to initial peak height against OD of total carbon, one can observe a dependence of the reaction progression on particle thickness (Fig. 5). OD of total carbon (indicating particle thickness) was chosen here as a proxy of size instead of particle radius since low contrast for some of the particles prevented reliable determination of cross-sectional area and shape from the absorption profile. In addition, under higher humidity conditions, the particles were not spherical anymore, but tended to spread out beyond half spheres (see supporting information). Under those conditions, the size as determined by the projected area would not be the appropriate measure of the radius of the particles. The ozonolysis progresses faster for thinner particles. The change in ratio is proportional to a change in concentration of shikimic acid, which should be independent of particle size in case of a volume limited reaction (Eq. 1). A diffusion limited reaction, on the other hand, depends on the ratio of surface to volume (Eq. 3), which is larger for small particles. It can easily be seen why when considering the reacto-diffusive length $l$ (Eq. 9), which describes how far a gaseous molecule can diffuse before it reacts:

$$
l=\sqrt{\frac{D_{\mathrm{O}_{3}}}{k_{\mathrm{O}_{3}}^{\mathrm{I}}}} .
$$




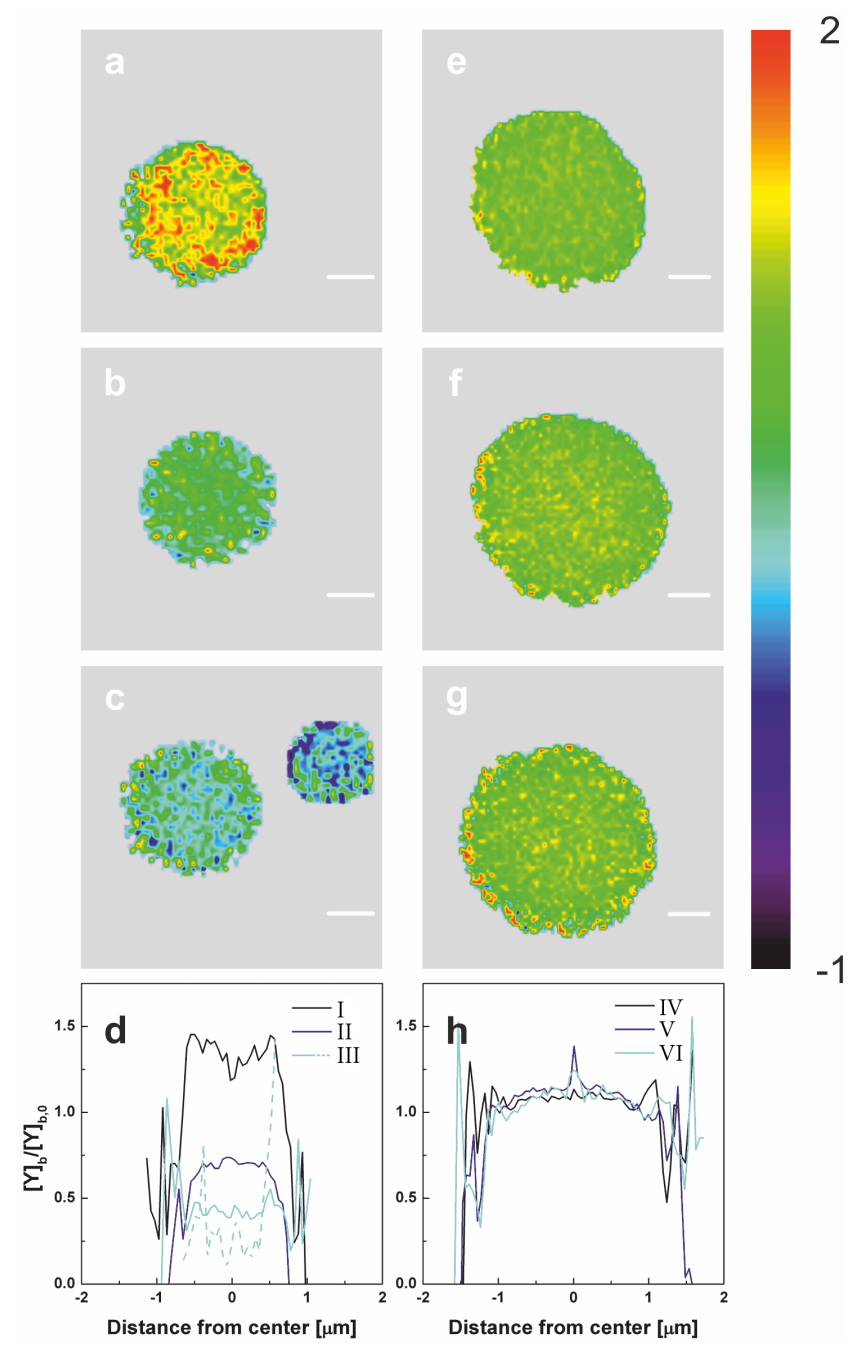

Figure 6. Depletion of shikimic acid via the decrease of OD at the maximum of the $1 \mathrm{~s}-\pi^{*}$ transition peak around $284.4 \mathrm{eV}$ normalized to total carbon. (a-c) show the progress of the reaction for four different particles at $71 \% \mathrm{RH}$ at $\mathrm{O}_{3}$ doses of $0 \mathrm{atms}$ (a), $5.0 \times 10^{-2} \mathrm{~atm} s$ (b) and $7.7 \times 10^{-2} \mathrm{~atm} s$ (c). (d) depicts the respective radial profiles of the particles: (I) (black line), (II) (dark blue line) and (III) (light blue lines, solid (larger particle) and dashed (smaller particle)). (e-g) show the progress of the reaction for three different particles at $12 \% \mathrm{RH}$ with $\mathrm{O}_{3}$ doses of $0 \mathrm{atms}$ (e), $1.4 \times 10^{-2}$ atm s (f) and $7.9 \times 10^{-2}$ atm s (g). (h) depicts the radial profiles of the imaged particles: (IV) (black line), (V) (dark blue line) and (VI) (light blue line). The scale bar denotes $500 \mathrm{~nm}$. The the appearance of clusters of red pixels at the edge of some of the particles arises from alignment issues combined with the relatively low contrast of the carbon K-edge measurements. The images show that no observable concentration gradient has formed at either humidity.

Smaller particles have a higher surface to volume ratio so that the thin layer in which the reaction takes place takes up a proportionally larger part of the total particle volume. Using the $k^{\mathrm{II}}$ value estimated in 3.2 , one can calculate $k_{\mathrm{O}_{3}}^{\mathrm{I}}$.
Under the assumption that we have a liquid of low viscosity at $82 \% \mathrm{RH}\left(D_{\mathrm{O}_{3}}=1 \times 10^{-5} \mathrm{~cm}^{2} \mathrm{~s}^{-1}\right)$, the reacto-diffusive length is $253 \mathrm{~nm}$. Taking the estimates of the diffusion coefficients obtained above, the values of $l$ range from 70 to $0.9 \mathrm{~nm}$ from $71 \% \mathrm{RH}$ to $12 \% \mathrm{RH}$. Thus, this would provide an a posteriori justification for the assumption made in Sect. 3.2 that from $71 \% \mathrm{RH}$ to $12 \% \mathrm{RH}$ the reacto-diffusion limited is the more likely scenario ( $l$ is much smaller than the particle dimension/thickness), while at $82 \%$ extracting the rate constant under the bulk reaction limited regime would be warranted, especially since the particles at this humidity spread to a shape thinner than hemispherical. Of course formation of an oxidized layer could further influence the uptake due to a change in physical parameters affecting the phase transfer, but a decrease in viscosity remains vital in formation of such a layer. It is also a possibility that reaction products could in general affect viscosity of the particle. Different product yields at different humidities could therefore lead to unforeseeable effects on diffusivity, a possibility neglected in our data evaluation. Further uncertainties arise from the fact that the concept of reacto-diffusive length is strictly speaking only valid for cases in which the bulk reactant is well mixed. Due to the not so well-defined shape of the particles at higher humidity, we also refrain from application of a correction to Eq. (3) to account for non-planar surfaces.

\subsection{Chemical maps}

For a highly viscous particle with low diffusion coefficients, a gradient of the condensed phase reactant might build up in the bulk material, as suggested by Shiraiwa et al. (2011) for the case of ozonolysis of a protein. The kinetic analysis at different humidities and the size dependence have also led us to suggest that the reaction occurs within a thin layer close to the surface (for the medium and lower humidities) and that the differences between the humidities would be attributed to a change in diffusion coefficient by four orders of magnitude. It would thus be conceivable to assume that the diffusion coefficient of shikimic acid could become low enough so that the diminished exchange within the bulk phase leads to a gradient within the particles. Therefore, we extracted chemical maps showing the distribution of the double bond throughout the particles at various steps of the oxidation process at $12 \% \mathrm{RH}, 52 \% \mathrm{RH}$ and $71 \% \mathrm{RH}$. Figure $6 \mathrm{a}-\mathrm{c}$ show the progress of the oxidation for different particles at $71 \% \mathrm{RH}$. These figures again clearly show that the concentration of the double bond decreases with an increasing $\mathrm{O}_{3}$ dose (Sect. 3.1). In Fig. 6c, one can clearly see that the smaller particle of the two is oxidized to a larger degree than the larger one (Sect. 3.3). This decrease occurs homogeneously throughout the particle, as would be expected for particles at high humidity, where the diffusivity of shikimic acid is likely large enough to allow sufficient exchange throughout the particle, in spite of the fact that the actual reaction occurs within the reacto-diffusive depth of $\mathrm{O}_{3}$. 
The radial profiles in Fig. 6d support this conclusion. Also at $52 \% \mathrm{RH}$ no gradient was apparent in spite of measurable overall degradation. Plots (e)-(g) in Fig. 6, on the other hand, depict the progress of oxidation at $12 \% \mathrm{RH}$. No oxidation is observable, as also seen from the radial profiles in Fig. $6 \mathrm{~h}$. Progression of the reaction from the surface towards the interior was obviously too slow to be observed within the duration of the experiment, and the layer of oxidized material too thin to become apparent within the resolution of the method. As estimated above, the reacto-diffusive length of $\mathrm{O}_{3}$ would be $0.9 \mathrm{~nm}$ at this humidity. Accordingly, the integrated analysis of many more particles shown in Fig. 3 likewise does not show an apparent degradation under these dry conditions. To demonstrate the capability of the method to actually identify marked chemical gradients at the scale of more than about $100 \mathrm{~nm}$, we show an image of a particle with an accidental contamination as an inclusion in the supporting online material (Fig. S4). The lack of a visible gradient combined with the existence of size dependence points to a classic reactodiffusive case where a gradient only exists in $\mathrm{O}_{3}$, while the bulk material is well mixed for humidities at and above $52 \%$. Under conditions where the diffusion coefficient of ozone drops to $1 \times 10^{-10} \mathrm{~cm}^{2} \mathrm{~s}^{-1}$, it is likely that the self-diffusion coefficients can be very low, easily below $10^{-16} \mathrm{~cm}^{2} \mathrm{~s}^{-1}$ in magnitude (Koop et al., 2011). Thus, if the location of oxidation is confined to a layer of thickness $l$ of $0.9 \mathrm{~nm}$ estimated above, it would take $280 \mathrm{~h}$ for the oxidation front to migrate over more than $100 \mathrm{~nm}$ for $D=10^{-16} \mathrm{~cm}^{2} \mathrm{~s}^{-1}$ so that it could become apparent in our STXM images, which was beyond the timescale of our experiment. To resolve a gradient, we propose using a different model system to which one of the two following conditions apply. The easiest case would be a system where diffusion of the bulk reactant is already so low that full exchange of bulk molecules does not happen on timescales of the experiments (such as in our low humidity case), but with a diffusion of the small gas phase reactant which is still sufficiently high to guarantee reaction over an observable distance. Proteins, in which small molecules can move via percolation, might be one such system. Shiraiwa et al. (2012) have suggested such gradients to occur during nitration of proteins. Another conceivable situation would be that the ratio of the diffusion coefficient to the first order loss rate constant would be of the same order of magnitude for the two reacting species. Since for the conditions of a STXM experiment, the condensed phase reactant needs to be at high concentrations to provide sufficient dynamic range, only very soluble oxidants would be feasible for such experiments.

\section{Conclusions and implications}

In this study, we demonstrated that in situ STXM/NEXAFS is a useful tool to investigate the oxidation kinetics of liquid and semi-solid particles. We have successfully shown that the degradation kinetics of shikimic acid depends on humidity and is therefore likely influenced by their physical state. While the depletion curves alone do not provide enough information to distinguish between a bulk reaction limited case and reacto-diffusive limitation, additional information from the size dependence of the reaction points to reacto-diffusive limitation. No gradient of shikimic acid was observed in any of our measurements. Assuming reacto-diffusive limitation, this means that it is either beyond the spatial or temporal resolution of our method or that the limitation is only enforced by a gradient in $\mathrm{O}_{3}$.

This study shows that in the transition from aqueous liquid to semi-solid or glassy states at lower humidity, the oxidation of unsaturated organics is largely suppressed and confined to a thin surface layer. This increases the life time of reactive organic compounds by many orders of magnitude. Assuming the reaction is pseudo-first order with respect to $\mathrm{O}_{3}$, we can use the apparent first order rate constants listed in Table 1 to estimate atmospheric lifetimes. Using the Henry's law constant for $\mathrm{O}_{3}$ solubility in water at $298 \mathrm{~K}$ (Utter et al., 1992), we calculate a shikimic acid lifetime of 7.5 days at $82 \% \mathrm{RH}$, while the lifetime of particles at $12 \% \mathrm{RH}$ would be over 5 years at $40 \mathrm{ppb}$ atmospheric $\mathrm{O}_{3}$. Such large variations in atmospheric lifetime could for example influence source apportionments if the fate of a marker compound used for the latter is affected. In this case, one might need to take into account the temperature and humidity history of the air mass to make a valid assessment. In other terms, the increased viscosity in semi-solid or glassy particle extends the lifetime of toxic compounds.

It should be noted that according to our observations kinetic limitations become apparent already at $71 \% \mathrm{RH}$. On the other hand, the particles seem well mixed down to $52 \%$ RH and self-diffusion of shikimic acid only becomes limiting at very low humidities where the particles become glassy. One should therefore be careful to imply morphological implications such as a core-shell structure from the mere presence of reacto-diffusive limitation. The Supplement related to this article is available online
at doi:10.5194/acp-14-10761-2014-supplement. 
Acknowledgements. This work is supported by the EU FP7 project PEGASOS and by the Swiss National Science Foundation (grant no. 130175). E.C. was supported by a Swiss National Science Foundation International Short Visit grant (IZK0Z2_142687). The PolLux end station was financed by the German Minister für Bildung und Forschung (BMBF) through contracts 05KS4WE1/6 and 05KSWE. B. Watts, J. Raabe and B. Sarafimov were crucial in supporting the operation of our experimental infrastructure at the PolLux microscope. We thank M. Birrer for technical support and appreciate the helpful discussions with A. Huisman, U. Krieger, C. Marcolli and T. Peter.

Edited by: Y. Cheng

\section{References}

Berkemeier, T., Huisman, A. J., Ammann, M., Shiraiwa, M., Koop, T., and Pöschl, U.: Kinetic regimes and limiting cases of gas uptake and heterogeneous reactions in atmospheric aerosols and clouds: a general classification scheme, Atmos. Chem. Phys., 13, 6663-6686, doi:10.5194/acp-13-6663-2013, 2013.

Biń, A. K.: Ozone solubility in liquids, Ozone-Sci. Eng., 28, 67-75, 2006.

Bluhm, H, Andersson, K., Araki, T., Benzerara, K., Brown, G. E., Dynes, J. J., Ghosal, S., Gilles, M. K., Hansen, H.-Ch., Hemminger, J. C., Hitchcock, A. P., Ketteler, G., Kilcoyne, A. L. D., Kneedler, E., Lawrence, J. R., Leppard, G. G., Majzlam, J., Mun, B. S., Myneni, S. C. B., Nilsson, A., Ogasawara, H., Ogletree, D. F., Pecher, K., Salmeron, M., Shuh, D. K., Tonner, B., Tyliszczak, T., Warwick, T., and Yoon, T. H.: Soft X-ray microscopy and spectroscopy at the molecular environmental science beamline at the Advanced Light Source, J. Electron Spectrosc., 150, 86-104, 2006

Criegee, R.: Mechanism of ozonolysis, Angew. Chem. Int. Edit., 14, 745-752, 1975.

Debenedetti, P. G. and Stillinger, F. H.: Supercooled liquids and the glass transition, Nature, 410, 259-267, 2001.

Decesari, S., Facchini, M. C., Fuzzi, S., and Tagliavini, E.: Characterization of water-soluble organic compounds in atmospheric aerosol: a new approach, J. Geophys. Res.-Atmos., 105, 14811489, 2000.

Dhez, O., Ade, H., and Urquhart, S. G.: Calibrated NEXAFS spectra of some common polymers, J. Electron Spectrosc., 128, 85-96, 2003.

Drake, I. J., Liu, T. C. N., Gilles, M., Tyliszczak, T., Kilcoyne, A. L. D., Shuh, D. K., Mathies, R. A., and Bell, A. T.: An in situ cell for characterization of solids by soft X-ray absorption, Rev. Sci. Instrum., 75, 3242-3247, 2004.

Hitchcock, A. P.: aXis2000, available at: http://unicorn.mcmaster. ca/aXis2000.html (last access: 11 March 2014), 1998.

Hoigné, J. and Bader, H.: Rate constants of reactions of ozone with organic and inorganic-compounds in water, 1. Non-dissociating organic-compounds, Water Res., 17, 173-183, 1983.

Hopkins, R. J., Tivanski, A. V., Marten, B. D., and Gilles, M. K.: Chemical bonding and structure of black carbon reference materials and individual carbonaceous atmospheric aerosols, J. Aerosol Sci., 38, 573-591, 2007.

Huthwelker, T., Zelenay, V., Birrer, M., Krepelova, A., Raabe, J., Tzvetkov, G., Vernooij, M. G. C., and Ammann, M.: An in situ cell to study phase transitions in individual aerosol particles on a substrate using Scanning Transmission x-ray Microspectroscopy, Rev. Sci. Instrum., 81, 113706, doi:10.1063/1.3494604, 2010.

Ivleva, N. P., McKeon, U., Niessner, R., and Pöschl, U.: Raman microspectroscopic analysis of size-resolved atmospheric aerosol particle samples collected with an ELPI: soot, humic-like substances, and inorganic compounds, Aerosol Sci. Tech., 41, 655671, 2007.

Jacobsen, C., Wirick, S., Flynn, G., and Zimba, C.: Soft x-ray spectroscopy from image sequences with sub- $100 \mathrm{~nm}$ spatial resolution, J. Microsc.-Oxford, 197, 173-184, 2000.

Kanakidou, M., Seinfeld, J. H., Pandis, S. N., Barnes, I., Dentener, F. J., Facchini, M. C., Van Dingenen, R., Ervens, B., Nenes, A., Nielsen, C. J., Swietlicki, E., Putaud, J. P., Balkanski, Y., Fuzzi, S., Horth, J., Moortgat, G. K., Winterhalter, R., Myhre, C. E. L., Tsigaridis, K., Vignati, E., Stephanou, E. G., and Wilson, J.: Organic aerosol and global climate modelling: a review, Atmos. Chem. Phys., 5, 1053-1123, doi:10.5194/acp-51053-2005, 2005.

Kelly, S. T., Nigge, P., Prakash, S., Laskin, A., Wang, B., Tyliszczak, T., Leone, S. R., and Gilles, M. K.: An environmental sample chamber for reliable scanning transmission x-ray microscopy measurements under water vapor, Rev. Sci. Instrum., 84, 73708-73709, 2013.

Koop, T., Bookhold, J., Shiraiwa, M., and Pöschl, U.: Glass transition and phase state of organic compounds: dependency on molecular properties and implications for secondary organic aerosols in the atmosphere, Phys. Chem. Chem. Phys., 13, 19238-19255, 2011.

Kuwata, M. and Martin, S. T.: Phase of atmospheric secondary organic material affects its reactivity, P. Natl. Acad. Sci. USA, 109, 17354-17359, 2012.

Maria, S. F., Russell, L. M., Gilles, M. K., and Myneni, S. C. B.: Organic aerosol growth mechanisms and their climate-forcing implications, Science, 306, 1921-1924, 2004.

Medeiros, P. M. and Simoneit, B. R. T.: Source profiles of organic compounds emitted upon combustion of green vegetation from temperate climate forests, Environ. Sci. Technol., 42, 83108316, 2008.

Mikhailov, E., Vlasenko, S., Martin, S. T., Koop, T., and Pöschl, U.: Amorphous and crystalline aerosol particles interacting with water vapor: conceptual framework and experimental evidence for restructuring, phase transitions and kinetic limitations, Atmos. Chem. Phys., 9, 9491-9522, doi:10.5194/acp-9-9491-2009, 2009.

Moffet, R. C., Henn, T., Laskin, A., and Gilles, M. K.: Automated chemical analysis of internally mixed aerosol particles using $\mathrm{X}$ ray spectromicroscopy at the carbon k-edge, Anal. Chem., 82, 7906-7914, 2010.

Moffet, R. C., Rödel, T. C., Kelly, S. T., Yu, X. Y., Carroll, G. T., Fast, J., Zaveri, R. A., Laskin, A., and Gilles, M. K.: Spectromicroscopic measurements of carbonaceous aerosol aging in Central California, Atmos. Chem. Phys., 13, 10445-10459, doi:10.5194/acp-13-10445-2013, 2013.

Moise, T. and Rudich, Y.: Reactive Uptake of Ozone by AerosolAssociated Unsaturated Fatty Acids: Kinetics, Mechanism, and Products, J. Phys. Chem., 106, 6469-6476, 2002. 
Murray, B. J.: Inhibition of ice crystallisation in highly viscous aqueous organic acid droplets, Atmos. Chem. Phys., 8, 54235433, doi:10.5194/acp-8-5423-2008, 2008.

Perraud, V., Bruns, E. A., Ezell, M. J., Johnson, S. N., Yu, Y., Alexander, M. L., Zelenyuk, A., Imre, D., Chang, W. L., Dabdub, D., Pankow, J. F., and Finlayson-Pitts, B. J.: Nonequilibrium atmospheric secondary organic aerosol formation and growth, $\mathrm{P}$. Natl. Acad. Sci. USA, 109, 2836-2841, 2012.

Pöhlker, C., Wiedemann, K. T., Sinha, B., Shiraiwa, M., Gunthe, S. S., Smith, M., Su, H., Artaxo, P., Chen, Q., Cheng, Y. F., Elbert, W., Gilles, M. K., Kilcoyne, A. L. D., Moffet, R. C., Weigand, M., Martin, S. T., Pöschl, U., and Andreae, M. O.: Biogenic potassium salt particles as seeds for secondary organic aerosol in the Amazon, Science, 337, 1075-1078, 2012.

Pöschl, U.: Atmospheric aerosols: composition, transformation, climate and health effects, Angew. Chem. Int. Edit., 44, 7520-7540, 2005.

Raabe, J., Tzvetkov, G., Flechsig, U., Böge, M., Jaggi, A., Sarafimov, B., Vernooij, M. G. C., Huthwelker, T., Ade, H., Kilcoyne, D., Tyliszczak, T., Fink, R. H., and Quitmann, C.: PolLux: a new facility for soft x-ray spectromicroscopy at the Swiss Light Source, Rev. Sci. Instrum., 79, 113704, doi:10.1063/1.3021472, 2008.

Razumovskii, S. D. and Zaikov, G. E.: Kinetics and mechanism of ozone reactions with dual reactivity points, Usp. Khim.+, 49, 2344-2376, 1980.

Renbaum, L. H. and Smith, G. D.: The importance of phase in the radical-initiated oxidation of model organic aerosols: reactions of solid and liquid brassidic acid particles, Phys. Chem. Chem. Phys., 11, 2441-2451, 2009.

Rogge, W. F., Mazurek, M. A., Hildemann, L. M., Cass, G. R., and Simoneit, B. R. T.: Quantification of urban organic aerosols at a molecular-level - identification, abundance and seasonalvariation, Atmos. Environ., 27, 1309-1330, 1993.

Russell, L. M., Maria, S. F., and Myneni, S. C. B.: Mapping organic coatings on atmospheric particles, Geophys. Res. Lett., 29, 1779, doi:10.1029/2002g1014874, 2002.

Saukko, E., Lambe, A. T., Massoli, P., Koop, T., Wright, J. P., Croasdale, D. R., Pedernera, D. A., Onasch, T. B., Laaksonen, A., Davidovits, P., Worsnop, D. R., and Virtanen, A.: Humiditydependent phase state of SOA particles from biogenic and anthropogenic precursors, Atmos. Chem. Phys., 12, 7517-7529, doi:10.5194/acp-12-7517-2012, 2012.

Saxena, P. and Hildemann, L.: Water-soluble organics in atmospheric particles: a critical review of the literature and application of thermodynamics to identify candidate compounds, J. Atmos. Chem., 24, 57-109, 1996.

Shiraiwa, M. and Seinfeld, J. H.: Equilibration timescale of atmospheric secondary organic aerosol partitioning, Geophys. Res. Lett., 39, L24801, doi:10.1029/2012gl054008, 2012.

Shiraiwa, M., Pfrang, C., and Pöschl, U.: Kinetic multi-layer model of aerosol surface and bulk chemistry (KM-SUB): the influence of interfacial transport and bulk diffusion on the oxidation of oleic acid by ozone, Atmos. Chem. Phys., 10, 3673-3691, doi:10.5194/acp-10-3673-2010, 2010.

Shiraiwa, M., Ammann, M., Koop, T., and Pöschl, U.: Gas uptake and chemical aging of semisolid organic aerosol particles, P. Natl. Acad. Sci. USA, 108, 11003-11008, 2011.
Shiraiwa, M., Selzle, K., Yang, H., Sosedova, Y., Ammann, M., and Pöschl, U.: Multiphase Chemical Kinetics of the Nitration of Aerosolized Protein by Ozone and Nitrogen Dioxide, Environ. Sci. Technol., 46, 6672-6680, 2012.

Steimer, S. S., Te, Y.-F., Lienhard, D. M., Huisman, A. J., Ammann, M., and Krieger, U. K.: Electrodynamic balance measurements of thermodynamic, kinetic, and optical properties of aerosol not constrained by bulk data, manuscript in preparation for Atmospheric Measurement Techniques, 2014.

Takahama, S., Gilardoni, S., Russell, L. M., and Kilcoyne, A. L. D.: Classification of multiple types of organic carbon composition in atmospheric particles by Scanning Transmission X-ray Microscopy analysis, Atmos. Environ., 41, 9435-9451, 2007.

Utter, R. G., Burkholder, J. B., Howard, C. J., and Ravishankara, A. R.: Measurement of the mass accommodation coefficient of ozone on aqueous surfaces, J. Phys. Chem.-US, 96, 4973-4979, 1992.

Virtanen, A., Joutsensaari, J., Koop, T., Kannosto, J., Yli-Pirila, P., Leskinen, J., Makela, J. M., Holopainen, J. K., Pöschl, U., Kulmala, M., Worsnop, D. R., and Laaksonen, A.: An amorphous solid state of biogenic secondary organic aerosol particles, Nature, 467, 824-827, 2010.

Worsnop, D. R., Morris, J. W., Shi, Q., Davidovits, P., and Kolb, C. E.: A chemical kinetic model for reactive transformations of aerosol particles, Geophys. Res. Lett., 29, 1996, doi:10.1029/2002g1015542, 2002.

Yeung, M. C., Lee, A. K. Y., and Chan, C. K.: Phase transition and hygroscopic properties of internally mixed Ammonium Sulfate and Adipic Acid (AS-AA) particles by optical microscopic imaging and raman spectroscopy, Aerosol Sci. Tech., 43, 387-399, 2009.

Zahardis, J. and Petrucci, G. A.: The oleic acid-ozone heterogeneous reaction system: products, kinetics, secondary chemistry, and atmospheric implications of a model system - a review, Atmos. Chem. Phys., 7, 1237-1274, doi:10.5194/acp-7-1237-2007, 2007.

Zelenay, V., Ammann, M., Krepelova, A., Birrer, M., Tzvetkov, G., Vernooij, M. G. C., Raabe, J., and Huthwelker, T.: Direct observation of water uptake and release in individual submicrometer sized ammonium sulfate and ammonium sulfate/adipic acid particles using x-ray microspectroscopy, J. Aerosol Sci., 42, 38-51, 2011a.

Zelenay, V., Huthwelker, T., Krepelova, A., Rudich, Y., and Ammann, M.: Humidity driven nanoscale chemical separation in complex organic matter, Environ. Chem., 8, 450-460, 2011b.

Zelenay, V., Mooser, R., Tritscher, T., Křepelová, A., Heringa, M. F., Chirico, R., Prévôt, A. S. H., Weingartner, E., Baltensperger, U., Dommen, J., Watts, B., Raabe, J., Huthwelker, T., and Ammann, M.: Aging induced changes on NEXAFS fingerprints in individual combustion particles, Atmos. Chem. Phys., 11, 11777-11791, doi:10.5194/acp-11-11777-2011, 2011.

Zhang, Q., Jimenez, J. L., Canagaratna, M. R., Allan, J. D., Coe, H., Ulbrich, I., Alfarra, M. R., Takami, A., Middlebrook, A. M., Sun, Y. L., Dzepina, K., Dunlea, E., Docherty, K., DeCarlo, P. F., Salcedo, D., Onasch, T., Jayne, J. T., Miyoshi, T., Shimono, A., Hatakeyama, S., Takegawa, N., Kondo, Y., Schneider, J., Drewnick, F., Borrmann, S., Weimer, S., Demerjian, K., Williams, P., Bower, K., Bahreini, R., Cottrell, L., Griffin, R. J., Rautiainen, J., Sun, J. Y., Zhang, Y. M., and 
Worsnop, D. R.: Ubiquity and dominance of oxygenated species in organic aerosols in anthropogenically-influenced Northern Hemisphere midlatitudes, Geophys. Res. Lett., 34, L13801, doi:10.1029/2007g1029979, 2007.

Zhou, S., Shiraiwa, M., McWhinney, R. D., Pöschl, U., and Abbatt, J. P. D.: Kinetic limitations in gas-particle reactions arising from slow diffusion in secondary organic aerosol, Faraday Discuss., 165, 391-406, 2013.
Zobrist, B., Marcolli, C., Pedernera, D. A., and Koop, T.: Do atmospheric aerosols form glasses?, Atmos. Chem. Phys., 8, 52215244, doi:10.5194/acp-8-5221-2008, 2008.

Zobrist, B., Soonsin, V., Luo, B. P., Krieger, U. K., Marcolli, C., Peter, T., and Koop, T.: Ultra-slow water diffusion in aqueous sucrose glasses, Phys. Chem. Chem. Phys., 13, 3514-3526, 2011. 